\title{
Factor Affecting Investment Behavior: Mediating Role of Self-Efficacy
}

\author{
Fouz Khalid*
}

\begin{abstract}
Based on the theory of planned behavior, the study has examined the effects of risk tolerance, investment confidence, financial literacy, herding behavior on investment behavior with financial self-efficacy as an intervening variable among the investors of the stock market in Pakistan. The study has collected 350 sample responses from the investors of Pakistan Stock Exchange (PSX) using five-point Likert scale questionnaire. The study has employed PLS-SEM for data analysis using Smart PLS version 3.2.9. The results showed that investment confidence, and risk tolerance has positively significant relationship with financial self-efficacy while herding behavior has negatively significant relationship with financial self-efficacy. However, financial literacy has positive but statistically insignificant relationship with financial self-efficacy. Lastly, financial self-efficacy has positively significant relationship with investment behavior. Therefore, based on the research findings, it is recommended that financial investors should ensure that they design policies that enable them to learn from their own experience through reflection. Thus, they will be able to effectively learn from past trading experience, thereby reducing the risk of behavioral bias in trading stocks. Therefore, improving investor self-reflection capacity should be the focus of these educational programs.
\end{abstract}

Keywords: Financial Self-Efficacy, Financial Literacy, Investment Behavior, Stock Market.

\section{Introduction}

The investment behavior of the people or participants in market has made both practitioners and academicians interested to understand their behavior in order to manage the portfolio, financial asset and risk management. The markets that have been in efficient working, new set of information does not incur costs. Also, these sets of information can be converted into asset price, so the investors could quickly evaluate the financial assets based on rational expectations (Chang, Cheng, \& Khorana, 2000). Although, in the perspective of a real world the process of acquiring information might be costly, also few of the decisions of investment could be made on the basis of framework of investor's rational expectations. In addition, investors also tend to discard their set of information and use or adopt towards other investor's decisions. This aspect has been known as herding behavior (Huang \& Wang, 2017). The governments risk mitigation strategies very criticized in the beginning due to the decreasing profit in the economic downturns. One major problem that came to light was low wager of the employee and increased burden of expenditure (dos Santos Felipe, 2019). Expenses have multiplied, necessary expenses like home rent, groceries or maintenance serve as a major setback. Unemployed individuals face more drawbacks, Unexpected expenses like medical charges are very serious issue (Magendans, Gutteling, \& Zebel, 2017).

\footnotetext{
*SG Allied Business Limited, Karachi. Email: fouz.khalid19@gmail.com
} 
Policy makers have noticed another pressing concern like negative saving rates, high credit card debt and increased personal bankruptcies, now the policy makers have decided to educate people and teach them about financial literacy. This is very important because the policy makers have concluded that this knowledge will help individuals in meeting their day to day expenses and save some resources for further short comings (Rashid et al., 2020). Another problem that came in the light was behavior of investment based on investor, it is a common perception that investors tend to be more stereotype and overact in market due to perception of pattern similarity. So it is argued that the investors have inaccurate market knowledge (Kumari \& Sar, 2017).

Some investors have a bad habit of overestimating their skills as an investor and having a bogus size of confidence. Sometimes they intend to outperform the market to gain maximum profit ratios. There is sufficient information available on the market for the investors to gain profit from but they anchor on previously collected information and rely on their skills. The objective of the current study is to understand the investment behavior and identify the factors which play pivotal role in investment decision. Moreover, to find out how financial self-efficacy as a mediator can contribute to the investment decision.

\section{Literature Review}

\section{Theoretical Background}

In the context of social psychological ground, Ajzen (1991) introduced the theory named as a theory of planned behavior in which he introduces the concept to predict human behavior. This theory explains all the factors, which influence the behavior of an individual when a person does an action based on his or her behavior. This theory explains the three following concept: the negative or positive evaluation form by a person when an individual starts to behave in a particular way, second is the subjective norm which defines when individual actions are forced by the social activities that he or she has to perform in the selective way (Husin \& Alrazi, 2017). The last one is perceived behavioral control that explains the perception of the people, which extracted form an individual behavior. According to Warsame and Ireri (2016), this study helps to understand and predict human behavior in many studies. As stated,, in many investment behavior studies this theory has been applied very well. According to the previous studies, the outcome has been analyzed that there is a gap in terms of behavior studies in the capital market and interesting to investigate. The authors extracted the subjective norms, attitudes and behavior that have a control effect on investment in the capital market. Moreover, according to the above information further, discuss the different results that this is obvious that interest of the capital market affected by the interest of the investors. In the perspective of subjective norms and behavior have zero impact on the investment interest. Lastly, Warsame and Ireri (2016) has applied this theory by using Sukuk investment and it has a positive impact on influence on behavior intention. 


\section{Financial Self-efficacy and Investment Behavior}

Claudia and Murniati (2018) defined financial self-efficacy as a collection of psychological traits that include overloading, procrastination, regrets and risk aversion, mental accounting, or budgeting knowledge. Self-efficacy is the conviction that a person may accomplish a certain function with his ability. Investment behavior is dependent on potential volatility and is thus dangerous (Chatterjee, Finke, \& Harness, 2011). In a report on entrepreneurial self-efficacy, the researchers claimed that individuals with a high degree of entrepreneurial self-efficacy often appear to show greater financial regulation. In the theory of planned behavior, it has been suggested that when individuals assume the behavior is under their hands and have the potential to demonstrate a particular behavior, then assumed behavioral regulation or self-efficacy will influence actions explicitly (Ismail et al., 2017). Amagir, Wilschut, and Groot (2018) analyzed entrepreneurs' self-efficacy actions and concluded that entrepreneurs who had more faith in their entrepreneurial ability displayed more communication, management, and financial planning skills. Thus we hypothesize:

H1: Financial self-efficacy has a significant effect on investment behavior.

\section{Financial Literacy and Financial Self-Efficacy}

Financial self-efficacy relates to one's assumptions regarding one's capacity to meet a financial objective or mission (Farrell, Fry, \& Risse, 2016). Financial literacy is the willingness to grasp the money management techniques and implement them properly. Efficient financial preparation, sound risk control, correct interest estimation, and comprehension of the time value of capital are all aspects of financial literacy. Financial literacy increases tax preparation, the willingness to save and invest in diverse financial assets, and capital creation by improved benefit policy, insurance programs, and stock market investment. Montford and Goldsmith (2016) also found a positive result and concludes that Financial literacy is important because if you know about it, it can show you how to be effective about your finances so that you can accomplish more objectives and ambitions, quicker and eventually improve your financial self-efficacy. Financial literacy has improved financial efficacy, which will save you from being at a significant disadvantage to financial performance (Earl, Gerrans, Asher, \& Woodside, 2015). Thus, we proposed:

H2a: Financial literacy has a significant effect on financial self-efficacy.

$H 2 b$ : Financial literacy has a significant effect on investment decision with the mediation of financial self-efficacy.

\section{Risk Tolerance and Financial Self-Efficacy}

Lim, Heckman, Montalto, and Letkiewicz (2014) described financial risk tolerance as 'the greatest amount of ambiguity that anyone is prepared to consider when making a financial decision.' Prior researches have generally established a supportive association 
between financial self-efficacy and risk tolerance. While it is widely accepted that individuals hate danger, the degree of risk aversion varies among individuals, and therefore the same stimuli will contribute to specific individual reactions (Zhu, 2019). He found that individuals who were high in financial expertise were likely to allocate their funds to high-risk assets because they have a firm belief in their capabilities. Proof in the literature shows that consumers who have a strong trust in their skills and understanding of a financial system or are more acquainted with the system prefer to believe the product is less risky and can also have better risk tolerance (Hemrajani \& Sharma, 2018). Therefore, we hypothesize:

H3a: Risk tolerance has a significant effect on financial self-efficacy. H3b: Risk tolerance has a significant effect on investment decision with the mediation of financial self-efficacy.

\section{Herding Behavior and Financial Self-Efficacy}

According to Stevenson, Ciuchta, Letwin, Dinger, and Vancouver (2019), herding's behavior refers to how group behavior influences individual decisions. Work on the herding behavior of humans in general (including herding studies on financial markets) provides extensive proof that herding is at least partly a reaction to feeling uncertain on how to treat the stimulus posed. Given this aversion to the uncertain - identified by Kumari and Sar (2017) as fear of the unfamiliar concerning uncertainty - individuals are likely to use heuristic availability, which includes depending intuitively on the knowledge that is more available to the mind, including (but not limited to) knowledge that is viewed as important because it comes from a community to which one belongs. This trend indicates that individuals who really fear confusion and danger are more likely to be herded as they use the heuristic quality often and focus on knowledge that is excellent and more readily accessible to the mind because it would also increase their financial effectiveness anyway (Shneor \& Munim, 2019). Hence we proposed:

H4a: Herding behavior has a significant effect on financial self-efficacy. H4b: Herding behavior has a significant effect on investment decision with the mediation of financial self-efficacy.

\section{Investment Confidence and Financial Self-Efficacy}

Hoffmann and Post (2016) defines investor confidence as the ability of investors to participate in investment opportunities and associated forms of intermediation open to them, centered on their view of risk and return. Mauer, Neergaard, and Linstad (2017) have found a positive association between confidence and financial self-efficacy. Miao, Qian, and Ma (2017) have postulated that confidence people pursue their efforts to produce optimal outcomes and therefore trade more. Such people are vigilant, systematic, conscientious, coordinated, well prepared, hardworking, and driven to achievement. Such characteristics offer the person a degree of confidence in their financial management capability. Individuals of high confidence have well-defined investment priorities. These entities are highly organized and need close consideration, as well as firm plans to invest 
in long-term strategies of investment. Extremely confident individuals are self-assured of their critical capabilities and have a strong degree of financial self-efficacy (Boda \& Sunitha, 2018). Thus, we hypothesize:

H5a: Investment confidence has a significant effect on financial self-efficacy.

H5b: Investment confidence has a significant effect on investment decision with the mediation of financial self-efficacy.

Figure 1

Conceptual Framework

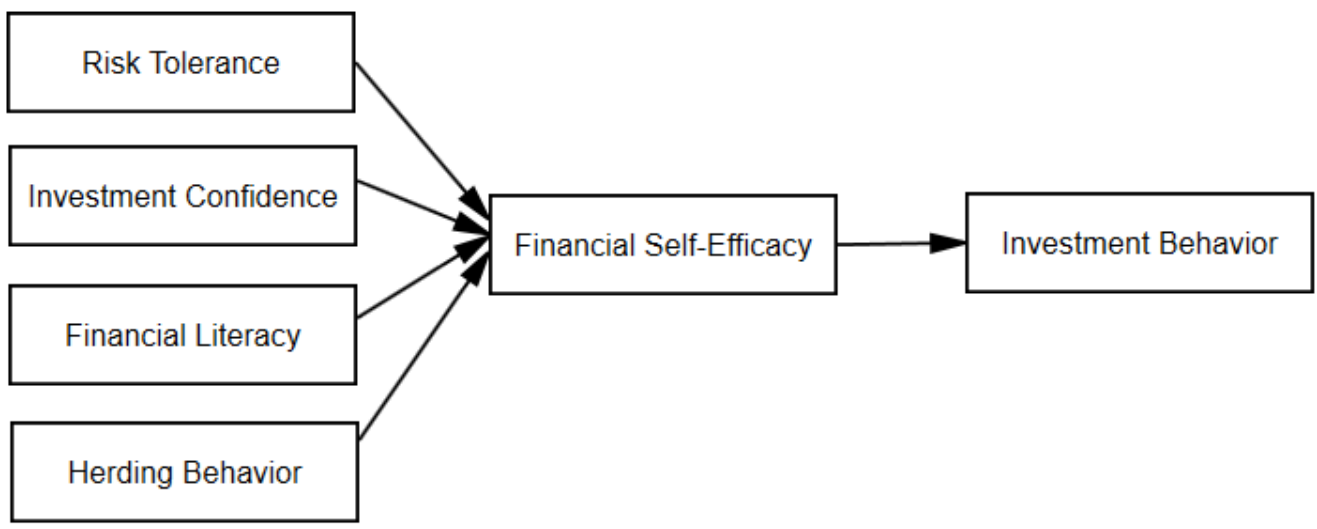

\section{Methodology}

sample population. A questionnaire was designed to use as a survey instrument to record respondents experience on a five-point Likert-type scale that varied from "strongly disagree" ' 1 ' to "strongly agree" ' 5 '. According to the formula suggested by Hair, Ringle, and Sarstedt (2013), the minimum recommended sample size was 290. However, in this study, the total number of gathered data was 350, fulfilling the criteria. In order to collect the sample, purposive sampling technique was used as the sample was drawn based on some specific purpose. In this case, the researcher aimed to select people based on their judgment because of its necessity that it provides more in-depth and close to the point results.

\section{Data Analysis Technique}

The statistical analysis provides results of data and its details and PLS-SEM is one the technique. The PLS-SEM helps in generating more variance and significant results with simultaneous analysis of relationships (Hair et al., 2013). Also, the PLS-SEM technique 
does not discriminate between high sample sizes or small, it conducts analysis on small or abnormal data with same effectiveness. The SEM is a second generation technique of data analysis for providing high significance of results. Therefore, this study has used PLS-SEM technique via SmartPLS 3.2.8 employing PLS algorithm, PLS bootstrapping and PLS blindfolding.

\section{Data Analysis}

\section{Respondents' Profile}

Table 1 presents the comprehensive detail about the participants of the study. The collected data reveals that 52\% (182) participants are male and 48\% (168) are male. Majority of the respondents (30\%) are less than 25 years of age, $28 \%$ more than 45 years of age, $24 \%$ are from 36-45 age group and 8\% belong to 26-35 age group. Based on the data collected, it is revealed that all the participants have at least one or more than year investment experience and 30\% respondents are earning less than 25,000 on monthly basis.

\begin{tabular}{|c|c|c|c|}
\hline & & Frequency & Percent \\
\hline \multirow[t]{4}{*}{ Age Group } & Less than 25 years & 105 & 30 \\
\hline & $26-35$ years & 63 & 18 \\
\hline & $36-45$ years & 84 & 24 \\
\hline & More than 45 years & 98 & 28 \\
\hline \multirow[t]{2}{*}{ Gender } & Male & 182 & 52 \\
\hline & Female & 168 & 48 \\
\hline \multirow{3}{*}{ Education } & Undergraduate & 112 & 32 \\
\hline & Graduate & 168 & 48 \\
\hline & Post-Graduate & 70 & 20 \\
\hline \multirow{4}{*}{ Monthly Income } & Less than 25000 & 105 & 30 \\
\hline & $25001-50000$ & 70 & 20 \\
\hline & $50001-100000$ & 84 & 24 \\
\hline & More than 100000 & 91 & 26 \\
\hline \multirow[t]{4}{*}{ Investment Experience } & Less than 1 year & 98 & 28 \\
\hline & $1-3$ years & 126 & 36 \\
\hline & $3-5$ years & 56 & 16 \\
\hline & More than 5 years & 70 & 20 \\
\hline
\end{tabular}

\section{Measurement Model}

In PLS-SEM, measurement model refers to the computational method for relationship between measures and their respective constructs (Afthanorhan, 2013). Herein, the following table shows the result of measurement model comprising factor loadings for each measure, Cronbach's alpha and composite reliability for internal consistency of the latent constructs and average variance extracted (AVE). 


\begin{tabular}{lccccc}
$\begin{array}{l}\text { Table } 2 \\
\text { Measurement Model }\end{array}$ & & & & & \\
\hline Variables & Items & Loadings & Alpha & CR & AVE \\
\hline Financial Literacy & FL3 & 0.851 & 0.701 & 0.869 & 0.768 \\
& FL5 & 0.901 & & & \\
Financial Self-Efficacy & FSE1 & 0.787 & 0.834 & 0.880 & 0.650 \\
& FSE2 & 0.739 & & & \\
& FSE3 & 0.933 & & & \\
FSE5 & 0.75 & & & \\
Herding Behavior & HB3 & 0.969 & 0.818 & 0.907 & 0.830 \\
Investment Behavior & HB5 & 0.849 & & & \\
& IB1 & 0.957 & 0.909 & 0.936 & 0.785 \\
& IB2 & 0.92 & & & \\
In3 & 0.809 & & & \\
& IB4 & 0.85 & & & \\
Investment Confidence & IC1 & 0.882 & 0.927 & 0.946 & 0.777 \\
& IC2 & 0.952 & & & \\
& IC3 & 0.901 & & & \\
& IC4 & 0.868 & & & \\
Risk Tolerance & IC5 & 0.797 & & & \\
& RT1 & 0.986 & 0.946 & 0.972 & 0.945 \\
& RT4 & 0.959 & & & \\
\hline
\end{tabular}

According to Hair Jr, Hult, Ringle, and Sarstedt (2016), factor loadings should be higher than 0.70 for construct validity, Cronbach's alpha should be higher than 70 percent, composite reliability should be higher than 80 percent for considerable internal consistency, whereas AVE should be higher than 50 percent for substantial degree of convergence between indicators. Herein, above table showed that factor loadings are higher than 0.70 while alpha, CR and AVE are also found higher than their respective thresholds. Thereby, measurement model has shown substantial results for construct and convergent validity.

\section{Discriminant Validity}

Discriminant validity refers to the computational method for checking relative difference between latent constructs in the measurement model. Herein, the study has used two methods for discriminant validity including Fornell and Larcker (1981) criterion, and cross loadings. However, HTMT ratio was found used in the study due to higher HTMT ratio of 0.926 between risk tolerance and herding behavior while Henseler, Ringle, and Sarstedt (2015) recommended that HTMT ratio should be 0.90 at most.

\section{Fornell and Larcker Criterion}

According to Fornell and Larcker (1981), the difference between latent constructs can be assessed by comparing the square-root of AVE for individual constructs with the correlation coefficients of other latent constructs in the model. In case, the square-root of AVE found higher than the other correlation coefficients, discriminant validity has been achieved. In the above table, the bold diagonal coefficients are the square-rooted AVE of latent constructs and have found higher than other constructs. Thus, discriminant validity using Fornell and Larcker (1981) criterion has been achieved. 
Table 3

Fornell-Larcker Criterion

\begin{tabular}{lcccccc}
\hline & FL & FSE & HB & IB & IC & RT \\
\hline Financial Literacy & 0.876 & & & & & \\
Financial Self-Efficacy & -0.101 & 0.806 & & & & \\
Herding Behavior & -0.347 & 0.021 & 0.911 & & & \\
Investment Behavior & -0.006 & 0.71 & -0.014 & 0.886 & & \\
Investment Confidence & -0.188 & 0.549 & 0.030 & 0.572 & 0.882 & \\
Risk Tolerance & -0.299 & 0.033 & 0.837 & -0.019 & -0.072 & 0.972 \\
\hline
\end{tabular}

\section{Cross Loadings}

Another method for discriminant validity is the cross loadings that focuses on estimating the loadings of one indicator in all constructs and therein, the loading should be found higher in its particular construct contrasting to its loading in other constructs (Henseler et al., 2015). The following table 5 shows the result of cross loadings for discriminant validity.

\begin{tabular}{lcccccc}
\multicolumn{2}{l}{ Table 4 } \\
\multicolumn{7}{l}{ Cross Loadings } \\
\hline & FL & FSE & HB & IB & IC & RT \\
\hline FL3 & 0.851 & -0.080 & 0.058 & -0.018 & -0.210 & 0.024 \\
FL5 & 0.901 & -0.097 & -0.605 & 0.005 & -0.128 & -0.499 \\
FSE1 & -0.005 & 0.787 & 0.035 & 0.500 & 0.194 & 0.038 \\
FSE2 & 0.052 & 0.739 & 0.009 & 0.297 & 0.110 & 0.084 \\
FSE3 & 0.059 & 0.933 & -0.015 & 0.78 & 0.460 & 0.059 \\
FSE5 & -0.336 & 0.75 & 0.045 & 0.528 & 0.726 & -0.036 \\
HB3 & -0.292 & 0.024 & 0.969 & -0.018 & -0.004 & 0.799 \\
HB5 & -0.39 & 0.011 & 0.849 & -0.002 & 0.096 & 0.735 \\
IB1 & 0.039 & 0.653 & -0.03 & 0.957 & 0.488 & -0.019 \\
IB2 & 0.032 & 0.660 & -0.001 & 0.920 & 0.397 & -0.012 \\
IB3 & -0.048 & 0.403 & -0.002 & 0.809 & 0.245 & -0.053 \\
IB4 & -0.056 & 0.718 & -0.013 & 0.850 & 0.782 & 0.000 \\
IC1 & -0.089 & 0.489 & 0.018 & 0.654 & 0.882 & -0.068 \\
IC2 & -0.171 & 0.486 & 0.034 & 0.517 & 0.952 & -0.05 \\
IC3 & -0.215 & 0.549 & 0.02 & 0.613 & 0.901 & -0.104 \\
IC4 & -0.121 & 0.412 & -0.012 & 0.437 & 0.868 & -0.064 \\
IC5 & -0.223 & 0.465 & 0.069 & 0.267 & 0.797 & -0.025 \\
RT1 & -0.303 & 0.038 & 0.885 & -0.023 & -0.061 & 0.986 \\
RT4 & -0.272 & 0.022 & 0.699 & -0.011 & -0.086 & 0.959 \\
\hline
\end{tabular}

In above table, it has been shown that all indicators have factor loadings higher in their respective constructs while found less in other constructs. Therefore, discriminant validity using cross loadings has been achieved.

\section{Structural Model}

Structural model refers to the computational method in PLS-SEM for estimating the hypothesized relationship between latent constructs based on research framework of the study (Hair Jr et al., 2016). In this case, the study has used PLS bootstrapping technique for hypothesis-testing based on recommended 5000 subsamples and 90 percent confidence interval. 
Table 5

Hypothesis-Testing using Path Analysis

\begin{tabular}{lllll}
\hline & Estimate & S. D. & T-Stats & Prob. \\
\hline Financial Literacy - > Financial Self-Efficacy & 0.012 & 0.058 & 0.201 & 0.420 \\
Financial Self-Efficacy ->Investment Behavior & 0.710 & 0.024 & 29.027 & 0.000 \\
Herding Behavior - > Financial Self-Efficacy & -0.190 & 0.126 & 1.510 & 0.066 \\
Investment Confidence -> Financial Self-Efficacy & 0.574 & 0.038 & 15.08 & 0.000 \\
Risk Tolerance -> Financial Self-Efficacy & 0.236 & 0.117 & 2.026 & 0.021 \\
\hline
\end{tabular}

The results of path analysis showed that financial self-efficacy $(\beta=0.710, \mathrm{p}<0.10)$ has positively significant relationship with investment behavior accepting hypothesis-1. Hypothesis-2a postulating significant relationship between financial literacy and financial self-efficacy has been rejected as the results showed that financial literacy $(\beta=0.012$, $\mathrm{p}>0.10$ ) has positive but statistically insignificant relationship with financial self-efficacy. Hypothesis-3a postulating that risk tolerance has a significant relationship with financial self-efficacy has been accepted as the results showed that risk tolerance $(\beta=0.710, \mathrm{p}<$ 0.10 ) has positively significant relationship with financial self-efficacy. Hypothesis-4a postulating significant relationship between herding behavior and financial self-efficacy has been accepted as the results showed that herding behavior $(\beta=-0.190, \mathrm{p}<0.10)$ has negatively significant relationship with financial self-efficacy. Lastly, hypothesis-5a posited significant relationship between investment confidence and financial self-efficacy while the results also supported this hypothesis and shown that investment confidence $(\beta=$ $0.574, \mathrm{p}<0.10$ ) has positive and significant relationship with financial self-efficacy.

\section{Mediation Analysis}

Above table showed that hypothesis- $2 \mathrm{~b}$ postulating an indirect relationship between financial literacy and investment behavior with the mediation of financial self-efficacy $(\beta=$ $0.008, \mathrm{p}>0.10$ ) has been rejected. Hypothesis-3b postulating an indirect relationship between risk tolerance and investment behavior with the mediation of financial self-efficacy $(\beta=0.168, \mathrm{p}<0.10)$ has been accepted. Hypothesis- $4 \mathrm{~b}$ postulating an indirect relationship between herding behavior and investment behavior with the mediation of financial selfefficacy $(\beta=-0.135, \mathrm{p}<0.10)$ has been accepted. Hypothesis-5b postulating an indirect relationship between investment confidence and investment behavior with the mediation of financial self-efficacy $(\beta=0.408, \mathrm{p}<0.10)$ has been accepted.

Table 6

Mediation Analysis using PLS-SEM

\begin{tabular}{lcccc}
\hline & Estimate & Std. Dev. & T-Stats & Prob. \\
\hline Financial Literacy -> Financial Self-Efficacy ->Investment Behavior & 0.008 & 0.041 & 0.200 & 0.421 \\
Risk Tolerance - > Financial Self-Efficacy - > Investment Behavior & 0.168 & 0.083 & 2.026 & 0.021 \\
Herding Behavior - > Financial Self-Efficacy - > Investment Behavior & -0.135 & 0.089 & 1.508 & 0.066 \\
Investment Confidence -> Financial Self-Efficacy ->Investment Behavior & 0.408 & 0.034 & 11.913 & 0.000 \\
\hline
\end{tabular}




\section{Predictive Relevance}

Based on the recommended method, the study has used PLS blindfolding technique for estimating the predictive relevance and accuracy of the endogenous latent constructs in the model. The results of predictive relevance have been provided in the following table 8.

\begin{tabular}{llll}
$\begin{array}{l}\text { Table } 7 \\
\text { Predictive Relevance }\end{array}$ & & & \\
\hline & R Square & $\begin{array}{l}\text { R Square } \\
\text { Adjusted }\end{array}$ & Q Square \\
\hline Financial Self-Efficacy & 0.318 & 0.310 & 0.156 \\
Investment Behavior & 0.505 & 0.503 & 0.370 \\
\hline
\end{tabular}

\section{Conclusion and Recommendations}

The present research paper investigated the factors affecting investment behavior along with financial self-efficacy as an intervening variable among the stock market investors. The results of this research identified highly significant results except for financial literacy and helped in the understanding of the investment behavior of the investors. For instance, herding behavior was found significantly related with financial self-efficacy and this result identified that when the investors engaged in high herd behavior than it increased their self-efficacy and helped in taking the adequate decisions regarding investment. In addition, risk tolerance was significantly related with financial self-efficacy and it helped the investors to effectively identify the risk factors and conduct their financial based on the risk tolerance. Additionally, investment confidence was significantly related with financial self-efficacy and this result was generated because when the investors had effective knowledge and confidence in their understanding towards it than it helped in increasing their self-efficacy as well. Besides, financial self-efficacy was significantly related with investment behavior and this results was main finding. This result helped in understanding and identifying that the increase in personal belief regarding the abilities that a task can be achieved in a positive way it eventually helped in developing the investment behavior of the investors.

\section{Managerial Recommendations}

The study concluded that risk tolerance has a positive and significant impact on financial self-efficacy. Therefore, based on the results of the research, it has been recommended to financial advisers/planners, professional organizations (financial services), and industry regulators. In particular, risk tolerance or risk perception should be considered in the consultation process so that financial advisers can provide appropriate advice to their clients. However, it is also recommended to financial investors that they should try to understand if there is any discrepancy between risk tolerance and perception. Thus, risk tolerance tends to change easily because it reflects how individuals view the risks of investment products. Therefore, financial advisers can intervene in this decision-making process by 
influencing investors' risk perception (for example, providing more risk education) and helping financial authorities to prepare for future investment. Besides that realistic decision according to risk from the perspective of financial services regulators and professional organizations would be taken to reduce the risk of the firm and increase the productivity, however, it has been recommended to the investors that they should consider producing guidance that requires financial advisers to assess risk tolerance and perception capabilities to reduce the risk factor The study concluded that financial self-efficacy can positively and significantly affect investment behavior. Therefore, based on this finding, it is recommended that financial investors and government should focus on education and training programs for their investors to increase their knowledge, understanding, thereby increasing confidence to manage financial investment behavior. Furthermore, the ability of their investors to manage financial behavior, however, this information will be relayed back to investors, thereby indirectly improving the financial self-efficacy of investors and society as a whole. Besides, this research also suggests to investors that they should enhance their self-assuredness, or self-belief, in their own capacity to manage their personal finances and successfully handle any financial challenges they may encounter that when investors believe that their high level of financial self-efficacy is higher than their actual level of financial knowledge, it will also increase

The study concluded that herding behavior has a positive and significant impact on financial self-efficacy. Therefore, based on the research findings, it is recommended that financial investors should ensure that they design policies that enable them to learn from their own experience through reflection. Thus, they will be able to effectively learn from past trading experience, thereby reducing the risk of behavioral bias in trading stocks. Therefore, improving investor self-reflection capacity should be the focus of these educational programs. However, to maximize investor benefits, they will participate in the stock market while enabling them to engage in social learning through peer relationships. However, the study also suggests that investors should focus on effective knowledgebased decision making with less risk, and investors should continue to focus on learning behaviors, which will ultimately secure more funding opportunities for lower cost, thereby promoting sustainable economic development.

The study concluded that investment confidence has a positive and significant impact on financial self-efficacy therefore, based on the results of the research, it has been recommended to financial advisers/planners, professional organizations, and industry regulators that financial service providers need to increase personal confidence in financial management and the use of formal financial products and services so that financial stakeholders can change financial behaviors, thereby realizing it. However, the enhancement of individuals' investors' confidence in evaluating the financial service options available will increase, which will lead them to make financial decisions that can improve their livelihoods.

\section{Future Research Directions}

The future research is very diverse in this study. The target population includes the investors of the stock market in Karachi, Pakistan. One of the recommendations is the sam- 
ple size used for this study was very small. The future researchers can use a larger sample size as they could collect more data from the investors of the stock market and also increase the period from which the data was taken. Also, since this study was limited because it used the quantitative research approach, it is a recommendation to future researchers that they should select qualitative researches to reach final conclusions that are detailed and could provide in-depth aspects on the topic. The study used five point likert scale which proved out to be a limitation in the study. Its recommended to use a 7 or a 9 point likert scale as it would further enhance the findings of the study and provide varying and detailed findings on the topic.

In addition, future research can focus on determining the risk tolerance curve for social media interaction intensity and determining the level of effective and ineffective exercise intensity and can overcome this by extending similar research to other types of markets (developed and emerging markets), different types of behavioral biases (such as experimental and potential trends), and other types of investors (such as institutional investors and financial analysts). 


\section{References}

Afthanorhan, W. (2013). A comparison of partial least square structural equation modeling (PLS-SEM) and covariance based structural equation modeling (cb-sem) for confirmatory factor analysis. International Journal of Engineering Science and Innovative Technology, 2(5), 198-205.

Amagir, A., Wilschut, A., \& Groot, W. (2018). The relation between financial knowledge, attitudes towards money, financial self-efficacy, and financial behavior among high school students in the Netherlands. Empirische Pädagogik, 32(3/4), 387-400.

Boda, J. R., \& Sunitha, G. (2018). Investor's psychology in investment decision making: A behavioral finance approach. International Journal of Pure and Applied Mathematics, 119(7), 1253-1261.

Chang, E. C., Cheng, J. W., \& Khorana, A. (2000). An examination of herd behavior in equity markets: An international perspective. Journal of Banking $\mathcal{E}$ Finance, 24(10), 1651-1679.

Chatterjee, S., Finke, M., \& Harness, N. (2011). The impact of self-efficacy on wealth accumulation and portfolio choice. Applied Economics Letters, 18(7), 627-631.

Claudia, G., \& Murniati, M. P. (2018). Self efficacy as the moderating variable in framing effect on investment decision making. South East Asia Journal of Contemporary Business, Economics and Law, 16(1), 22-27.

Earl, J. K., Gerrans, P., Asher, A., \& Woodside, J. (2015). Financial literacy, financial judgement, and retirement self-efficacy of older trustees of self-managed superannuation funds. Australian Journal of Management, 40(3), 435-458.

Farrell, L., Fry, T. R., \& Risse, L. (2016). The significance of financial self-efficacy in explaining women's personal finance behaviour. Journal of Economic Psychology, 54, 85-99.

Fornell, C., \& Larcker, D. F. (1981). Structural equation models with unobservable variables and measurement error: Algebra and statistics. Sage Publications Sage CA: Los Angeles, CA.

Hair, J. F., Ringle, C. M., \& Sarstedt, M. (2013). Partial least squares structural equation modeling: Rigorous applications, better results and higher acceptance. Long Range Planning, 46(1-2), 1-12.

Hair Jr, J. F., Hult, G. T. M., Ringle, C., \& Sarstedt, M. (2016). A primer on partial least squares structural equation modeling (PLS-SEM). Sage publications.

Hemrajani, P., \& Sharma, S. K. (2018). Influence of urgency on financial risk-taking behavior of individual investors: the role of financial risk tolerance as a mediating factor. IUP Journal of Applied Finance, 24(1), 30-43.

Henseler, J., Ringle, C. M., \& Sarstedt, M. (2015). A new criterion for assessing discriminant validity in variance-based structural equation modeling. Journal of the Academy of Marketing Science, 43(1), 115-135.

Hoffmann, A. O., \& Post, T. (2016). How does investor confidence lead to trading? linking investor return experiences, confidence, and investment beliefs. Journal of Behavioral and Experimental Finance, 12, 65-78. 
Huang, T.-C., \& Wang, K.-Y. (2017). Investors' fear and herding behavior: Evidence from the Taiwan stock market. Emerging Markets Finance and Trade, 53(10), 2259-2278.

Husin, N., \& Alrazi, B. (2017). Renewable energy investment in malaysia: An integrated model in evaluating public decision making process. Journal of Clean Energy Technologies, 5(4), 343-346.

Ismail, S., Faique, F. A., Bakri, M. H., Zain, Z. M., Idris, N. H., Yazid, Z. A., ... Taib, N. M. (2017). The role of financial self-efficacy scale in predicting financial behavior. Advanced Science Letters, 23(5), 4635-4639.

Kumari, N., \& Sar, A. K. (2017). Cognitive and behavioral biases influencing investment performance. ZENITH International Journal of Multidisciplinary Research, 7(8), 49-62.

Lim, H., Heckman, S., Montalto, C. P., \& Letkiewicz, J. (2014). Financial stress, selfefficacy, and financial help-seeking behavior of college students. Journal of Financial Counseling and Planning, 25(2), 148-160.

Magendans, J., Gutteling, J. M., \& Zebel, S. (2017). Psychological determinants of financial buffer saving: The influence of financial risk tolerance and regulatory focus. Journal of Risk Research, 20(8), 1076-1093.

Mauer, R., Neergaard, H., \& Linstad, A. K. (2017). Self-efficacy: Conditioning the entrepreneurial mindset. In Revisiting the entrepreneurial mind (pp. 293-317). Springer.

Miao, C., Qian, S., \& Ma, D. (2017). The relationship between entrepreneurial self-efficacy and firm performance: a meta-analysis of main and moderator effects. Journal of Small Business Management, 55(1), 87-107.

Montford, W., \& Goldsmith, R. E. (2016). How gender and financial self-efficacy influence investment risk taking. International Journal of Consumer Studies, 40(1), 101-106.

Shneor, R., \& Munim, Z. H. (2019). Reward crowdfunding contribution as planned behaviour: An extended framework. Journal of Business Research, 103, 56-70.

Stevenson, R. M., Ciuchta, M. P., Letwin, C., Dinger, J. M., \& Vancouver, J. B. (2019). Out of control or right on the money? funder self-efficacy and crowd bias in equity crowdfunding. Journal of Business Venturing, 34(2), 348-367.

Warsame, M. H., \& Ireri, E. M. (2016). Does the theory of planned behaviour (TPB) matter in sukuk investment decisions? Journal of Behavioral and Experimental Finance, 12, 93-100.

Zhu, A. Y. F. (2019). Financial risk tolerance of hong kong adolescents: A hierarchical model. Children and Youth Services Review, 102, 193-200. 